\title{
Heterogeneous impacts of climate change on crop yields across altitudes in Ethiopia
}

\author{
Tsegaye Ginbo ${ }^{1}$ (i)
}

Received: 1 February 2021 / Accepted: 7 January 2022 / Published online: 21 January 2022

(c) The Author(s) 2022

\begin{abstract}
Impacts of climate change can differ from one region to another. We combine the household-level panel data with weather and climate data to examine the heterogeneity of the impacts of climate change on crop yields across different crops and agro-ecologies in Ethiopia. Our results show that climate change will induce an increase in coffee and teff yields by $31 \%$ and $8.3 \%$, respectively, at high altitudes by the years 2041-2060 compared to 1988-2018, under a medium emissions scenario. Conversely, it will reduce coffee yield by $3 \%$ at low altitudes, and barley, maize, and wheat yield by $22.7 \%, 48 \%$, and $10 \%$, respectively, at high altitudes. These findings suggest that tailoring agricultural development programs and climate adaptation strategies to address location and crop-specific sensitivity to climate change may help to build resilience and improve the livelihood of smallholder farmers.
\end{abstract}

Keywords Climate change $\cdot$ Crop yields $\cdot$ Production risk $\cdot$ Climate resilience

\section{Introduction}

Climate change is likely to have different impacts on agriculture in different agro-ecological locations. Differences in altitudes can characterize differences in climatic factors, in particular temperature and precipitation, and their rate of change. As argued by Kolstad and Moore (2019), the effects of climatic changes can vary as a function of initial climatic conditions in a given location. For instance, the influences of climatic change, especially an increase in temperature, can differ in cooler (high altitude) areas compared to warmer (low altitude) areas (see, e.g., Läderach et al. 2017; Moat et al. 2017; Ovalle-Rivera et al. 2015; Rahn et al. 2018).

Ethiopia has been experiencing the consequences of climatic changes including high temperature and more frequent droughts and floods (Danyo et al. 2017; World Bank 2021). Recurrent droughts and flooding have caused a significant damage to the Ethiopian agriculture in particular and the overall economy in general (see, e.g., Danyo et al. 2017).

Tsegaye Ginbo

tsegaye.ginbo@slu.se; tsegaye.ginbo@yahoo.com

1 Department of Economics, Swedish University of Agricultural Sciences, PO Box 7013, 75007 Uppsala, Sweden 
Difference in altitudes, land areas, and topography resulted in the diverse local climate within the country ranging from equatorial rainforest with high rainfall and humidity in the south and southwest to desert-like conditions in the north-east, east, and south-east lowlands (World Bank 2021). Moreover, the changes in the trends of temperature and precipitation in the country vary significantly across the main agro-ecological zones, namely Kolla (areas below 1,500 m altitude), Woinadega (1,500-2,300 m), and Dega (above 2,300 m), in different regions (Esayas et al. 2018; Taye et al. 2019). For example, a significant decreasing trend (up to $-100 \mathrm{~mm}$ ) in seasonal rainfall is observed in the northern and central-eastern parts of Ethiopia, while there was a significant increasing trend (up to $+60 \mathrm{~mm}$ ) around north-eastern and south-western parts of Ethiopia (Gebrechorkos et al. 2019). In addition, regions in Southern and Eastern parts of Ethiopia are often hit by severe droughts while regions in Western parts of Ethiopia suffer from flooding (World Bank 2021). Consequently, the differentiated analysis of the impacts of climatic changes on crop production and livelihoods may help identify the effective adaptation options to build climate-resilient and sustainable agriculture in various agro-ecologies.

In this regard, we aim to examine the heterogeneity of the impacts of climate change on crop yields at farm level across different altitudes in Ethiopia. Specifically, we investigate whether the effects of (i) changes in temperature and precipitation and (ii) farmers' adoption of irrigation technology on the mean yields of crops and its variability differ between low and high altitudes. We combine a household-level panel data on farm characteristics and agricultural production with weather and climate data. Using the estimated coefficients of weather variables, historical and future climate data, we further evaluate the impacts of future climatic changes on crop yields across altitudes.

Our analysis makes two main contributions to existing literature. Firstly, it provides the disaggregated analysis by establishing a clear distinction about the impacts of climate change between low and high altitudes. Currently, existing literature considers nationally or regionally aggregated impacts of climate change on crop yields and their variability (see, e.g., Burke and Emerick 2016; Chen et al. 2016; McCarl et al. 2008; Poudel and Kotani 2013; Zhang et al. 2017). However, global evidence shows that the impacts of climate change on agriculture are specific to crops and locations even within a country (see, e.g., Jones and Thornton 2003; Moat et al. 2017; Rahn et al. 2018; Ray et al. 2019). This implies that aggregated analyses of impacts of climate change may not provide a clear picture of the impacts as it masks variations among different altitudes within a country. Secondly, our study provides a comprehensive analysis of the impacts of climate change on the six main crops in Ethiopia using the new and updated scenarios for future emissions. Majority of existing studies in low-income countries commonly considered the impact of climate change on mean yields for a single crop, or analyze farm revenues using a cross-sectional approach. We estimate the effects of climate change on the dominant cash-crop, coffee, and the major cereals, namely teff, wheat, maize, barley, and sorghum, by 2041-2060 compared to 1988-2018 period. Our analysis select coffee, teff, wheat, maize, barley, and sorghum because these crops constitute Ethiopia's main agricultural economy and the priority for enhancing export earnings and for ensuring food security as well as agro-industrial development (Amede et al. 2017; Danyo et al. 2017; FDRE 2011). Our evaluation of the impacts of climate change employs the new future emission scenarios of the Coupled Model Intercomparison Projects 6 (CMIP6) considered for the new IPCC's Sixth Assessment Report (AR6) (see Hausfather 2019; Meinshausen et al. 2020).

Our empirical results indicate differences in the impacts of climate change across crops and across attitudes in Ethiopia. Specifically, we find that coffee yield decreases by $3 \%$ at low altitudes while it increases by $31 \%$ at high altitudes due to climate change by period 
2041-2060, under a medium emissions scenario, compared to 1988-2018. Similarly, teff yield increases by $8.3 \%$ at high altitudes, over 2041-2060. Conversely, our results show that barley, maize, and wheat yields decrease by $22.7 \%, 48 \%$, and $10 \%$ at high altitudes, respectively, towards 2041-2060. Furthermore, temperature reduces the coffee, maize, and sorghum production risk at low altitudes while it increases the risk at high altitudes. Our findings imply that location-specific and crop-specific policies of climate change adaptation can be vital to increase agricultural productivity of smallholder farmers in Ethiopia. The remainder of the paper is organized as follows. Section 2 presents the description of data and empirical methods employed in the paper. While Section 3 provides the empirical results, Section 4 highlights the discussion of the results and policy implications. Finally, Section 5 provides the concluding remarks.

\section{Materials and methods}

\subsection{Data and descriptive statistics}

This paper uses the data from the three main sources to estimate the effect of climate change on crop yield and its variability. First, we utilize the Ethiopia's Socioeconomic Survey (ESS) data, obtained from the World Bank, for information about household characteristics and agricultural activities. The ESS is a part of the Living Standards Measurement Study-Integrated Survey on Agriculture (LSMS-ISA) of the World Bank collected by the Central Statistical Agency of Ethiopia in 2011/2012, 2013/2014, and 2015/2016. It is a nationally representative data for rural households in the country (see Figure A1 in Appendix A). The survey employs the two-stage clustered sampling technique where the first stage involves the selection of the enumeration areas (EAs) and the second stage comprises the random selection of the sample households from the sample EAs. It covers 3,776 rural households in the first round, with the sample size increasing to 5,262 in the second and third rounds.

Based on the responses of farmers to the questions in ESS survey, we calculate our variables about land area under cultivation, farm input use, farm management practices, and crop yields. We compute crop yields in kilograms (kg) per hectare (ha) by using the farm area measured by GPS, or rope and compass, and the farmer-reported harvest in kilograms. Farmer's self-reported farm area in hectares is used whenever the area measured by GPS or rope and compass is missing. We consider the number of weeks and days worked by both men and women when calculating the total number of days family and hired labor worked during the crop planting and management activities. In our analysis, we have also included dummy variables indicating whether farmers adopted irrigation, improved seeds and soil erosion prevention systems, and obtained extension services. From the ESS data, we also compute the total kilograms of chemical fertilizer farmers applied on 1 ha of their land under barley, maize, sorghum, and wheat production. For coffee farmers, we create a dummy variable indicating whether they used manure or compost as fertilizers since the coffee production in Ethiopia is entirely organic, meaning farmers do not use any chemical fertilizer or pesticides. Education of the household head is indicated by the dummy variable constructed for whether they are literate.

Second, we obtain the data about weather and climate variables, the main variables of interest in our analysis, from the USA Climate Prediction Center, the Copernicus Climate Change Service, and the Climate Research Unit of the University of East Anglia. We use 
the average yearly precipitation data for the crop-growing season obtained from the USA Climate Prediction Center. This data was extracted by the ESS survey core team using each household's geographical location represented by latitudinal and altitudinal coordinates. In addition, we extract ERA5 anomalies of precipitation and temperature from the Copernicus Climate Change Service for crop-growing season in years 2011, 2013, and 2015 by using the geographical coordinates of farmers' location. ${ }^{1}$ Temperature and precipitation anomalies are the deviations from their average for the 1981-2010 period. To evaluate the impacts of future climate change on crop yields, we utilize the historical climate data for the past 30 years (1988-2018) provided by Climatic Research Unit of the University of East Anglia and CMIP6 future climate data of the IPSL-CM6A-LR for the 2021-2040 and 2041-2060 periods. $^{2}$ The future climate data we used represent four scenarios of the CMIP6, namely low (SSP1-2.6), middle of the road (SSP2-4.5), medium-high (SSP3-7.0), and high (SSP58.5) (see Figure A2 in Appendix A for the emissions trends under these scenarios).

As indicated by the descriptive statistics in Table 1 , there is a statistically significant difference in weather variables as well as the mean yields of coffee, barley, maize, teff, and sorghum crops between low and high altitudes. Yields are more likely higher in high altitudes than in low altitudes except for coffee (see Table 1). Coffee yields are higher at low altitudes as compared to high altitudes. In addition, the adoption of irrigation technology is generally low, and it slightly varies across places except for wheat. Moreover, high altitude areas receive a higher amount of precipitation and a lower amount of temperature as compared to low altitude areas, except the precipitation for the case of coffee producers. These differences in agro-ecological and climatic conditions can explain the differences in crop yields across different altitudes. However, determining whether climate change affects crop production differently in different locations poses an interesting empirical question into which our analysis attempts to provide an insight.

\subsection{Empirical framework}

We use the stochastic production function, specified in Eq. (1), where climatic and weather variables affect crop yields as well as the production risk, i.e., the variability of crop yields, in line with the framework initially developed by Just and Pope (1978). Our analysis considers a farmer who chooses farm inputs, given the exogenous climatic factors and fixed soil type and quality.

$$
Y_{i t}=F\left(X_{i t}, W_{i t}, I_{i t} ; \beta\right)+G\left(Z_{i t}, W_{i t}, I_{i t} ; \alpha\right) u_{i t}
$$

where $Y_{i t}$ is the $i$ farmer's per hectare yield of a crop during the production year $t ; F($. and $G($.$) represent the mean and variance (risk) component of the production function,$ respectively. $X_{i t}$ and $Z_{i t}$ represent farm inputs and farm management practices, and $W_{i t}$ is the weather conditions, such as precipitation and temperature during the production year, at location of $i$ farmer at time $t$. The variable $I_{i t}$ broadly represents the state of technology a farmer uses on their farm, and includes irrigation and machinery. The variance of a

\footnotetext{
1 ERA5 refers to the "fifth ReAnalysis" of the global climate. The data is provided by the European Centre for Medium-Range Weather Forecasts (https://cds.climate.copernicus.eu/cdsapp\#!/dataset/ecv-for-climatechange).

2 IPSL-CM6A-LR is the latest version of the Institut Pierre Simon Laplace climate model. Both historical and future climate data are generated from the WorldClim (https://www.worldclim.org/data/index.html).
} 
Table 1 Difference in crops yield and weather variables between low and high altitudes

\begin{tabular}{|c|c|c|c|c|c|}
\hline & \multicolumn{3}{|l|}{ Mean } & \multicolumn{2}{|c|}{ Mean Difference } \\
\hline & Group $(\mathrm{G}) 1$ & $\operatorname{Group}(\mathrm{G}) 2$ & Group $(\mathrm{G}) 3$ & G1 vs. G2 & G1(2) vs. G3 \\
\hline \multicolumn{6}{|l|}{ Coffee } \\
\hline Yield (kg/ha) & 6512.31 & 3317.51 & & $3194.80 * * *$ & \\
\hline Temperature $\left({ }^{\circ} \mathrm{C}\right)$ & 19.69 & 18.36 & & $1.33 * * *$ & \\
\hline Precipitation (mm) & 621.22 & 620.20 & & 1.02 & \\
\hline Irrigation (\%) & 0.08 & 0.03 & & $0.05 * * *$ & \\
\hline \multicolumn{6}{|l|}{ Barley } \\
\hline Yield (kg/ha) & 1330.75 & & 1737.22 & & $-406.47 * * *$ \\
\hline Temperature $\left({ }^{\circ} \mathrm{C}\right)$ & 18.64 & & 16.31 & & $2.33 * * *$ \\
\hline Precipitation (mm) & 589.49 & & 658.09 & & $-68.60 * * *$ \\
\hline Irrigation (\%) & 0.01 & & 0.004 & & $0.006 * *$ \\
\hline \multicolumn{6}{|l|}{ Maize } \\
\hline Yield (kg/ha) & 2773.37 & 3082.32 & 2745.23 & $-308.95 * * *$ & 337.09 \\
\hline Temperature $\left({ }^{\circ} \mathrm{C}\right)$ & 21.06 & 18.48 & 16.87 & $2.58 * * *$ & $1.61 * * *$ \\
\hline Precipitation (mm) & 568.26 & 657.37 & 727.13 & $-89.11 * * *$ & $-69.76 * * *$ \\
\hline Irrigation (\%) & 0.06 & 0.02 & 0.005 & $0.04 * * *$ & $0.015 * *$ \\
\hline \multicolumn{6}{|l|}{ Teff } \\
\hline Yield (kg/ha) & 674.76 & 977.90 & 1089.98 & $-303.14 * * *$ & $-112.08 * *$ \\
\hline Temperature $\left({ }^{\circ} \mathrm{C}\right)$ & 19.67 & 18.05 & 16.31 & $1.62 * * *$ & $1.74 * * *$ \\
\hline Precipitation (mm) & 578.47 & 665.57 & 784.70 & $-87.10 * * *$ & $-119.13 * * *$ \\
\hline Irrigation (\%) & 0.02 & 0.01 & 0.01 & $0.01 * * *$ & 0.0 \\
\hline \multicolumn{6}{|l|}{ Sorghum } \\
\hline Yield (kg/ha) & 1795.60 & 1956.84 & & $-161.24^{*}$ & \\
\hline Temperature $\left({ }^{\circ} \mathrm{C}\right)$ & 21.16 & 19.19 & & $1.97 * * *$ & \\
\hline Precipitation (mm) & 478.54 & 510.99 & & $-32.45^{* * *}$ & \\
\hline Irrigation (\%) & 0.09 & 0.02 & & $0.07 * * *$ & \\
\hline \multicolumn{6}{|l|}{ Wheat } \\
\hline Yield (kg/ha) & & 1516.86 & 1632.16 & & -115.30 \\
\hline Temperature $\left({ }^{\circ} \mathrm{C}\right)$ & & 17.89 & 16.51 & & $1.38 * * *$ \\
\hline Precipitation (mm) & & 572.91 & 701.12 & & $-128.21 * * *$ \\
\hline Irrigation (\%) & & 0.01 & 0.007 & & 0.003 \\
\hline
\end{tabular}

heteroskedastic error term, $G(.) u_{i t}$, is $\sigma_{u}^{2} G(.)^{2}$, where $G(.)^{2}$ assumed to take an exponential form $e^{\alpha Z_{i t}}$ with $\sigma_{u}^{2}=1$ to ensure positive variance (Isik and Devadoss 2006; Picazo-Tadeo and Wall 2011). In Just and Pope (J-P) production function framework, there is no prior restriction about the effect of inputs on production risk. Hence, a given input may increase risk if $G_{Z}>0$ or it may decrease risk if $G_{Z}<0 .{ }^{3}$ The term $u_{i t}$ is the stochastic disturbance term with mean zero and variance one, as indicated above, and $\beta$ and $\alpha$ in Eq. (1) are the parameters of the model. As a common practice in the J-P literature (see, e.g., Carew 2017; Carew et al. 2009; Chen et al. 2004; Isik and Devadoss 2006; McCarl et al. 2008;

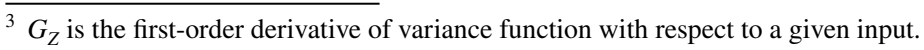


Picazo-Tadeo and Wall 2011; Poudel and Kotani 2013), we use the Cob-Douglas specification with the linear and quadratic forms of weather variables in the mean model but only the linear terms in the variance model.

In line with Eq. (1), we specify the panel data regression model, indicated in Eq. (2), where the effect of weather variables on a crop yield is represented by two parameters, namely the coefficients of the linear $\left(W_{i t}\right)$ and nonlinear $\left(W_{i t}{ }^{2}\right)$ terms of the logarithm of temperature and precipitation during the crop-growing season in year $t$ at household $i$ location. These are included to capture linear and extreme trends in weather and climate. We also control for the effect of conventional farm inputs on crop yields. $X_{i t}$ in Eq. (2) represents the vector of control variables, namely the natural logarithms of fertilizer used, family and hired labor, dummy variables representing farmer's use of improved seed, and extension services and mechanisms for soil erosion prevention. Moreover, we examine the effect of farmer climate adaptation, especially when coping with droughts or low rains through using the irrigation practice. For this purpose, $I_{i t}$, representing whether a farmer uses irrigation or not, is included in our model. The terms $\mu_{j}$ and $\tau_{t}$ stand for zonal and year fixed effects, respectively. The final term $\left(\varepsilon_{i t}\right)$ is the heteroskedastic standard error and has an expected value equal to zero.

$$
\log Y_{i t}=\alpha_{m} W_{i t}+\beta_{m} W_{i t}^{2}+\gamma_{m} I_{i t}+\delta_{m} X_{i t}+\mu_{j}+\tau_{t}+\varepsilon_{i t}
$$

We estimate the model in Eq. (2) by using the feasible generalized least squares (FGLS) procedure, given a heteroskedastic error term. FGLS is preferred since, as pointed out by Picazo-Tadeo and Wall (2011), the estimates from maximum likelihood fail to converge due to the inclusion of quadratic forms of weather variables in our model. Specifically, we first estimate Eq. (2) and obtain the predicted value of residuals. Second, the squared residuals, represented by Eq. (3), regressed on variables that can influence production risk.

$$
\log \left(\tilde{\varepsilon}_{i t}^{2}\right)=\alpha_{v} W_{i t}+\gamma_{v} I_{i t}+\gamma_{v} Z_{i t}+\mu_{t}+\tau_{t}+e_{j t}
$$

In addition to $X_{i t}$ control variables in Eq. (2), $Z_{i t}$ in Eq. (3) includes age and education of a household head to represent farmer's experience and farm management knowledge that can influence the crop production risk. The error term $\left(e_{j t}\right)$ has the expected value equal to zero. The regression of the model in Eq. (3) gives us estimates for the parameters $(\tilde{\alpha})$ and the predicted value of the variance function $(\tilde{G})$. We obtain Eq. (4) by transforming Eq. (2) using the predicted value of $\tilde{G}$ as weight. Equation (4) includes the weighted versions of the variables included in Eq. (3) and the weighted error term $\left(\bar{\varepsilon}_{j t}\right)$ having the mean value of zero. Finally, the estimation of Eq. (4) provides the consistent estimates of the parameters of our interest, i.e., effects of climatic variables and irrigation, $\bar{\alpha}_{m}$ and $\bar{\beta}_{m}$, and $\bar{\gamma}_{m}$, respectively, on the mean crop yields. Given the clustered sampling design of the ESS data used in this paper, we cluster standard errors at the level of enumeration area (EA) so that, as argued by Abadie et al. (2017), the estimated results can be generalized to farmers living in the clusters not included in the sample.

$$
\log \bar{Y}_{j t}=\bar{\alpha}_{m} \bar{W}_{i t}+\bar{\beta}_{m} \bar{W}_{i t}^{2}+\bar{\gamma}_{m} \bar{I}_{j t}+\bar{\delta}_{m} \bar{X}_{j t}+\bar{\mu}_{t}+\bar{\tau}_{j t}+\bar{\varepsilon}_{j t}
$$

Our specification allows us to obtain the plausibly causal estimates of the impacts of climatic variables on crop yields. This is because we exploit the random year-to-year exogenous variation in precipitation as well as temperature. The inclusion of a timeinvariant zonal fixed effect and the year fixed effect in our regression model controls 
for unobserved regional heterogeneity in terms of soil quality and farming tradition and for any exogenous shock including technological change across time, respectively. In addition, the coefficient on the higher-order term in Eq. (4) uses both within-unit time series variation and cross-sectional variation across units and this ensures the plausible estimates of the impacts of climate change that incorporate long-run adaptation (Auffhammer 2018).

We also test for the potential endogeneity of the decision to adopt irrigation technology. Table B1 in the Appendix B shows that there is no statistically significant correlation between irrigation adoption and household characteristics; however, there is a statistically significant correlation with household location indicators. Since the access to irrigation in Ethiopia is very much limited and the proportion of irrigated agricultural land remains below 1\% (Manyazewal and Shiferaw 2019), only those households closer to water sources or dams are likely to irrigate their farms. Hence, the estimate of irrigation coefficient in our mean and variance model of crop yields can be confounded by location-specific but time-invariant factors such as distance to water body. To control for this, we employ fixed effect estimation procedure in each of the three-stage regressions of FGLS by using the least square dummy variable method.

To find out whether the climatic variables have heterogeneous impacts on crop yields across altitudes, we categorize households in the sample into three or two groups based on the three traditional agro-ecological zones in Ethiopia, namely Kolla, Woinadega, and Dega. We estimate a separate regression model for each of the subgroups for each of the six crops for two main reasons. There are significant variations in agro-environmental conditions, including temperature and precipitation, among the three altitudinal categories (see, e.g., Esayas et al. 2018; Taye et al. 2019). The distribution of the crops also varies across three agro-ecologies where areas below $1500 \mathrm{~m}$ grow sorghum and rarely teff, areas between 1500 and 2300 grow wheat, maize, and teff, and areas above 2300 grow mainly barley and to some extent wheat (Hurni 1998). In the literature, regional differences were controlled in the regression by including the dummy variables for the administrative regions (e.g. Chen et al. 2016; McCarl et al. 2008; Poudel and Kotani 2013; Zhang et al. 2017). However, there can be a difference in climate among places in each administrative region since there can be various agro-ecological situations within a region. Therefore, our estimation of separate model for each agro-ecology in addition to controlling for administrative counties (zones in the Ethiopian context) helps us to investigate heterogeneity of climatic impacts among different agro-ecological zones. By estimating Eqs. (3) and (4) separately for each group, we determine whether the coefficients of climatic variables and adoption of irrigation have different signs across low and high altitudes.

As the robustness check to validate the reliability and sensitivity of empirical results, we estimate the model by using (1) the whole sample by including the interaction of altitude with rainfall and temperature instead of splitting the sample into altitudinal categories and (2) translog functional form instead of Cobb-Douglas specification.

Finally, we use the estimated coefficients of the model in Eq. (4) to evaluate impacts of future climate change on crop yields. For this purpose, we have taken the average climate data for the past 30 years (1988-2018) as a baseline to compute the impact of future climate change over the period 2041-2060. The data for future climate data is generated from CMIP6 climate model for the updated emission scenarios, namely SSP1-2.6, SSP24.5, and SSP5-8.5, and the new scenario SSP3-7.0. Assuming other variables in our regression models being constant, we compute the projected changes in crop yields $\left(\Omega_{t}\right)$ due to the future climate change, by following the procedure described in Chen et al. (2016) as indicated by Eq. (5). 
Table 2 Regression results for coffee and barley yields

\begin{tabular}{|c|c|c|c|c|c|c|c|c|}
\hline \multirow[t]{4}{*}{ Variables } & \multicolumn{4}{|l|}{ Coffee } & \multicolumn{4}{|l|}{ Barley } \\
\hline & \multicolumn{2}{|c|}{ Low altitudes } & \multicolumn{2}{|c|}{ High altitudes } & \multicolumn{2}{|c|}{ Low altitudes } & \multicolumn{2}{|c|}{ High altitudes } \\
\hline & (1) & (2) & (3) & (4) & (5) & (6) & (7) & (8) \\
\hline & Mean & Variance & Mean & Variance & Mean & Variance & Mean & Variance \\
\hline Temperature & $\begin{array}{l}-74.8 * * * \\
(24.20)\end{array}$ & $\begin{array}{l}-0.42 * * \\
(0.20)\end{array}$ & $\begin{array}{l}87.9 * \\
(49.96)\end{array}$ & $\begin{array}{l}1.1 * * * \\
(0.15)\end{array}$ & $\begin{array}{l}-7.67 \\
(16.82)\end{array}$ & $\begin{array}{l}0.16^{* * * *} \\
(0.02)\end{array}$ & $\begin{array}{l}43.69 * * * \\
(15.55)\end{array}$ & $\begin{array}{l}0.21 * * \\
(0.09)\end{array}$ \\
\hline $\begin{array}{l}\text { Temperature } \\
\text { squared }\end{array}$ & $\begin{array}{l}12.40 * * * \\
(4.10)\end{array}$ & & $\begin{array}{l}-14.4^{*} \\
(8.55)\end{array}$ & & $\begin{array}{l}1.39 \\
(2.91)\end{array}$ & & $\begin{array}{l}-7.73 * * * \\
(2.74)\end{array}$ & \\
\hline $\begin{array}{c}\text { Temperature } \\
\text { anomaly }\end{array}$ & (1.42) & $\begin{array}{l}-0.03 \\
(0.18)\end{array}$ & (1.35) & $(0.09)$ & $(0.35)$ & $0.05 * * *$ & $(0.60)$ & $(0.07)$ \\
\hline Precipitation & $\begin{array}{l}-40.64 \\
(37.35)\end{array}$ & $\begin{array}{l}0.74 * * * \\
(0.17)\end{array}$ & $\begin{array}{l}4.57 \\
(30.90)\end{array}$ & $\begin{array}{l}0.28 * * * \\
(0.07)\end{array}$ & $\begin{array}{l}10.06 \\
(6.53)\end{array}$ & $\begin{array}{l}0.05 * * * \\
(0.01)\end{array}$ & $\begin{array}{l}-4.51 \\
(3.67)\end{array}$ & $\begin{array}{l}-0.02 \\
(0.03)\end{array}$ \\
\hline $\begin{array}{l}\text { Precipitation } \\
\text { squared }\end{array}$ & $\begin{array}{l}3.48 \\
(3.04)\end{array}$ & & $\begin{array}{l}-0.37 \\
(2.43)\end{array}$ & & $\begin{array}{l}-0.79 \\
(0.52)\end{array}$ & & $\begin{array}{l}0.35 \\
(0.31)\end{array}$ & \\
\hline $\begin{array}{l}\text { Precipitation } \\
\text { anomaly }\end{array}$ & $\begin{array}{l}1.46 * * * \\
(0.48)\end{array}$ & $\begin{array}{l}0.63 * * * \\
(0.07)\end{array}$ & $\begin{array}{l}0.51 * \\
(0.26)\end{array}$ & $\begin{array}{l}0.17 * * * \\
(0.02)\end{array}$ & $\begin{array}{l}0.03 \\
(0.11)\end{array}$ & $\begin{array}{l}0.04 * * * \\
(0.00)\end{array}$ & $\begin{array}{l}0.07 \\
(0.10)\end{array}$ & $\begin{array}{l}-0.02 * * \\
(0.01)\end{array}$ \\
\hline Irrigation & $\begin{array}{l}2.04 * * * \\
(0.33)\end{array}$ & $\begin{array}{l}0.88 * * * \\
(0.07)\end{array}$ & $\begin{array}{l}0.53 \\
(0.49)\end{array}$ & $\begin{array}{l}0.23 * * * \\
(0.03)\end{array}$ & $\begin{array}{l}-0.17 \\
(0.29)\end{array}$ & $\begin{array}{l}-0.07 * * * \\
(0.01)\end{array}$ & $\begin{array}{l}-0.24 \\
(0.32)\end{array}$ & $\begin{array}{l}-0.04 * * * \\
(0.01)\end{array}$ \\
\hline$R$-squared & 0.52 & 0.98 & 0.43 & 0.98 & 0.23 & 0.99 & 0.27 & 0.97 \\
\hline Observations & 508 & 508 & 581 & 581 & 1,011 & 1,011 & 1,289 & 1,289 \\
\hline
\end{tabular}

Notes: The dependent variable in columns (1) and (3) and (5) and (7) is the log of coffee and barley yields, respectively, whereas it is the log of respective squared residual in columns (2) and (4) and (6) and (8). In the regression models, we control for zone and year fixed effects, farm inputs, farmer age, and education (see Table $\mathrm{C} 1$ in Appendix C). Standard errors are clustered at EA level and given in parentheses. $* * * p<0.01, * * p<0.05, * p<0.1$

$$
\Omega_{\mathrm{t}}=\mathrm{E}\left[\hat{\mathrm{Y}} \mid \text { Climate }_{2041-2060}\right]-\mathrm{E}\left[\hat{\mathrm{Y}} \mid \text { Climate }_{1988-2018}\right]
$$

In our specification of the crop yield as a function of linear and quadratic forms of climatic variables, Eq. (5) become:

$$
\Omega_{\mathrm{t}}=\widehat{\beta}_{1}\left[\mathrm{~W}_{2041-2060}-\mathrm{W}_{1988-2018}\right]+\widehat{\beta}_{2}\left[\mathrm{~W}^{2}{ }_{2041-2060}-\mathrm{W}^{2}{ }_{1988-2018}\right]
$$

\section{Empirical results}

This section presents the main empirical results while the discussion and policy implications are provided in Section 4. The regression results indicate the heterogeneity of the impacts of temperature on the mean and variance of crop yields at low and high altitudes. It is also interesting to note that mean yields are mainly affected by temperature in most cases 
Table 3 Regression results for maize yield model

\begin{tabular}{|c|c|c|c|c|c|c|}
\hline \multirow[t]{3}{*}{ Variables } & \multicolumn{2}{|c|}{ Low altitudes } & \multicolumn{2}{|c|}{ Middle altitudes } & \multicolumn{2}{|c|}{ High altitudes } \\
\hline & (1) & (2) & (3) & (4) & (7) & (6) \\
\hline & Mean & Variance & Mean & Variance & Mean & Variance \\
\hline Temperature & $\begin{array}{l}-2.70 \\
(11.60)\end{array}$ & $\begin{array}{l}-0.25^{* * *} \\
(0.01)\end{array}$ & $\begin{array}{l}17.03 \\
(17.56)\end{array}$ & $\begin{array}{l}0.18 * * * \\
(0.02)\end{array}$ & $\begin{array}{l}111.56^{* * * *} \\
(38.55)\end{array}$ & $\begin{array}{l}0.63 * * * \\
(0.17)\end{array}$ \\
\hline Temperature squared & $\begin{array}{l}0.28 \\
(1.88)\end{array}$ & & $\begin{array}{l}-2.82 \\
(3.02)\end{array}$ & & $\begin{array}{l}-19.36 * * * \\
(6.98)\end{array}$ & \\
\hline Temperature anomaly & $\begin{array}{l}-0.27 \\
(0.22)\end{array}$ & $\begin{array}{l}-0.08^{* * * *} \\
(0.01)\end{array}$ & $\begin{array}{l}0.08 \\
(0.32)\end{array}$ & $\begin{array}{l}0.01 \\
(0.01)\end{array}$ & $\begin{array}{l}-1.00 \\
(1.49)\end{array}$ & $\begin{array}{l}-0.25 \\
(0.21)\end{array}$ \\
\hline Precipitation & $\begin{array}{l}-1.13 \\
(3.17)\end{array}$ & $\begin{array}{l}-0.01^{* * *} \\
(0.00)\end{array}$ & $\begin{array}{l}-3.81 \\
(5.93)\end{array}$ & $\begin{array}{l}-0.00 \\
(0.01)\end{array}$ & $\begin{array}{l}-26.64 * \\
(14.50)\end{array}$ & $\begin{array}{l}0.03 \\
(0.06)\end{array}$ \\
\hline Precipitation squared & $\begin{array}{l}0.09 \\
(0.25)\end{array}$ & & $\begin{array}{l}0.31 \\
(0.47)\end{array}$ & & $\begin{array}{l}2.11^{*} \\
(1.19)\end{array}$ & \\
\hline Precipitation anomaly & $\begin{array}{l}-0.16 \\
(0.10)\end{array}$ & $\begin{array}{l}-0.06^{* * * *} \\
(0.00)\end{array}$ & $\begin{array}{l}0.14 * \\
(0.08)\end{array}$ & $\begin{array}{l}0.04 * * * \\
(0.00)\end{array}$ & $\begin{array}{l}0.30 * * \\
(0.13)\end{array}$ & $\begin{array}{l}0.08 * * * \\
(0.01)\end{array}$ \\
\hline Irrigation & $\begin{array}{l}-0.42 * * * \\
(0.11)\end{array}$ & $\begin{array}{l}-0.10^{* * *} \\
(0.00)\end{array}$ & $\begin{array}{l}0.08 \\
(0.10)\end{array}$ & $\begin{array}{l}0.02 * * * \\
(0.00)\end{array}$ & $\begin{array}{l}1.48 * * * \\
(0.31)\end{array}$ & $\begin{array}{l}0.40 * * * \\
(0.04)\end{array}$ \\
\hline$R$-squared & 0.32 & 1.00 & 0.31 & 0.99 & 0.35 & 0.93 \\
\hline Observations & 2,187 & 2,190 & 3,001 & 3,002 & 348 & 348 \\
\hline
\end{tabular}

Notes: The dependent variable in columns (1), (3), and (5) is log of maize yield, whereas it is log of squared residual in (2), (4), and (6). In the regression models, we control for zone and year fixed effects, farm inputs, farmer age, and education (see Table C2 in Appendix C). Standard errors are clustered at EA level and given in parentheses. $* * * p<0.01, * * p<0.05, * p<0.1$

whereas the variance of yields has statistically significant relationships with temperature, precipitation, and irrigation. Tables 2, 3, 4, 5 present the estimated coefficients of weather variables where the full results including the coefficients of all control variables are provided in Tables C1-C4, respectively in the Appendix C. We then provide the estimated impacts of future climate change on crop yields by period 2041-2060 in Table 6, where the impacts for the near-term period 2021-2040 presented in Table E1 in the Appendix E.

\subsection{Effects of weather variables on crop yields}

\subsubsection{Coffee yield}

As indicated in columns 1-4 of Table 2, weather variables affect coffee production differently across different altitudes. At low altitudes, temperature has a U-shaped relationship with the mean yield of coffee, whereas its effect is an inverted U-shaped at high altitudes. This nonlinear effect of temperature on mean yield of coffee at low and high altitudes is statistically significant at the $1 \%$ and $10 \%$ levels, respectively. In addition, the variability of coffee yield decreases with the increase in yearly temperature at low altitudes whereas it increases at high altitudes. Moreover, temperature anomaly has a positive and statistically significant effect on the mean yield of coffee at high altitudes. Unlike temperature, we do not find heterogeneity in the impacts of precipitation on the variability of coffee yields 
Table 4 Regression results for teff yield model

\begin{tabular}{|c|c|c|c|c|c|c|}
\hline \multirow[t]{3}{*}{ Variables } & \multicolumn{2}{|c|}{ Low altitudes } & \multicolumn{2}{|c|}{ Middle altitudes } & \multicolumn{2}{|c|}{ High altitudes } \\
\hline & (1) & (2) & (3) & (4) & (5) & (6) \\
\hline & Mean & Variance & Mean & Variance & Mean & Variance \\
\hline Temperature & $\begin{array}{l}0.24 \\
(20.99)\end{array}$ & $\begin{array}{l}0.42 * * * \\
(0.04)\end{array}$ & $\begin{array}{l}-13.50 \\
(17.09)\end{array}$ & $\begin{array}{l}0.16^{* * * *} \\
(0.02)\end{array}$ & $\begin{array}{l}-29.55^{* * * *} \\
(8.80)\end{array}$ & $\begin{array}{l}-0.27 * * * \\
(0.03)\end{array}$ \\
\hline Temperature squared & $\begin{array}{l}0.21 \\
(3.60)\end{array}$ & & $\begin{array}{l}2.39 \\
(2.98)\end{array}$ & & $\begin{array}{l}5.09 * * * \\
(1.57)\end{array}$ & \\
\hline Temperature anomaly & $\begin{array}{l}0.31 \\
(0.28)\end{array}$ & $\begin{array}{l}0.11 * * * \\
(0.02)\end{array}$ & $\begin{array}{l}-1.01^{* *} \\
(0.42)\end{array}$ & $\begin{array}{l}-0.27 * * * \\
(0.02)\end{array}$ & $\begin{array}{l}-0.96^{*} \\
(0.56)\end{array}$ & $\begin{array}{l}-0.22^{* * * *} \\
(0.07)\end{array}$ \\
\hline Precipitation & $\begin{array}{l}4.02 \\
(3.22)\end{array}$ & $\begin{array}{l}0.15 * * * \\
(0.02)\end{array}$ & $\begin{array}{l}10.05 * \\
(5.62)\end{array}$ & $\begin{array}{l}0.11 * * * \\
(0.02)\end{array}$ & $\begin{array}{l}-5.18 \\
(4.78)\end{array}$ & $\begin{array}{l}-0.13 * * * \\
(0.01)\end{array}$ \\
\hline Precipitation squared & $\begin{array}{l}-0.27 \\
(0.26)\end{array}$ & & $\begin{array}{l}-0.77^{*} \\
(0.44)\end{array}$ & & $\begin{array}{l}0.38 \\
(0.38)\end{array}$ & \\
\hline Precipitation anomaly & $\begin{array}{l}-0.02 \\
(0.08)\end{array}$ & $\begin{array}{l}-0.01 * \\
(0.00)\end{array}$ & $\begin{array}{l}0.11 \\
(0.09)\end{array}$ & $\begin{array}{l}0.05 * * * \\
(0.01)\end{array}$ & $\begin{array}{l}0.00 \\
(0.08)\end{array}$ & $\begin{array}{l}0.01 * * * \\
(0.00)\end{array}$ \\
\hline Irrigation & $\begin{array}{l}0.81 * * * \\
(0.09)\end{array}$ & $\begin{array}{l}0.25 * * * \\
(0.01)\end{array}$ & $\begin{array}{l}0.39 * * \\
(0.19)\end{array}$ & $\begin{array}{l}0.12 * * * \\
(0.01)\end{array}$ & $\begin{array}{l}0.16 \\
(0.22)\end{array}$ & $\begin{array}{l}0.03 * * * \\
(0.01)\end{array}$ \\
\hline$R$-squared & 0.32 & 0.99 & 0.37 & 0.98 & 0.32 & 0.98 \\
\hline Observations & 919 & 921 & 2,348 & 2,348 & 598 & 598 \\
\hline
\end{tabular}

Notes: The dependent variable in columns (1), (3), and (5) is log of teff yield, whereas in (2), (4), and (6) is $\log$ of the squared residual. In the regression models, we control for zone and year fixed effects, farm inputs, farmer age, and education (see Table C3 in Appendix C). Standard errors are clustered at EA level and given in parentheses. $* * * p<0.01, * * p<0.05,{ }^{*} p<0.1$

among low and high altitudes. The initial increase in precipitation significantly increases the variance of coffee yield at both low and middle altitude areas. Similarly, precipitation anomaly is found to have a positive and statistically significant effect on the mean coffee yield at both low and high altitudes. That means the increase in precipitation as compared to its long-term average increases the mean coffee yield. Our results also indicate that farmers' adoption of irrigation practices increases the mean yield of coffee at low altitudes whereas its effect is statistically insignificant at high altitudes. In addition, irrigation adoption increases the variability of coffee yield at both low and high altitudes. The discussion of our results in relation to the existing literature about the impacts of climate change on coffee crop production is given in Sub-Sect. 3.2.

\subsubsection{Barley yield}

Columns 5-8 of Table 2 present the estimated coefficients of weather variables in the barley yield model. Similar to coffee, we find a statistically significant inverted U-shaped relationship of temperature on the mean yield of barley at high altitudes, but its impacts are statistically insignificant at low altitudes. Initially, temperature increases barley yield but after certain threshold, the effect becomes negative. We find a positive relationship between the variability of barley yield and temperature at both low and high altitudes. The initial rise in precipitation also increases the variability of barley yield at low altitudes, but 
Table 5 Regression results for sorghum and wheat yields

\begin{tabular}{|c|c|c|c|c|c|c|c|c|}
\hline \multirow[t]{4}{*}{ Variables } & \multicolumn{4}{|l|}{ Sorghum } & \multicolumn{4}{|l|}{ Wheat } \\
\hline & \multicolumn{2}{|c|}{ Low altitudes } & \multicolumn{2}{|c|}{ High altitudes } & \multicolumn{2}{|c|}{ Low altitudes } & \multicolumn{2}{|c|}{ High altitudes } \\
\hline & (1) & (2) & (3) & (4) & (5) & (6) & (7) & (8) \\
\hline & Mean & Variance & Mean & Variance & Mean & Variance & Mean & Variance \\
\hline Temperature & $\begin{array}{l}-0.03 \\
(19.35)\end{array}$ & $\begin{array}{l}-0.22 * * * \\
(0.03)\end{array}$ & $\begin{array}{l}-26.88 \\
(18.89)\end{array}$ & $\begin{array}{l}0.25 * * * \\
(0.02)\end{array}$ & $\begin{array}{l}-24.38 \\
(22.25)\end{array}$ & $\begin{array}{l}0.18 * * * \\
(0.03)\end{array}$ & $\begin{array}{l}35.56^{*} \\
(20.57)\end{array}$ & $\begin{array}{l}0.05 \\
(0.04)\end{array}$ \\
\hline $\begin{array}{l}\text { Temperature } \\
\text { squared }\end{array}$ & $\begin{array}{l}-0.09 \\
(3.13)\end{array}$ & & (3.23) & & $\begin{array}{l}4.26 \\
(3.76)\end{array}$ & & $\begin{array}{l}-6.15^{*} \\
(3.55)\end{array}$ & \\
\hline $\begin{array}{l}\text { Temperature } \\
\text { anomaly }\end{array}$ & $(0.32)$ & $(0.02)$ & $\begin{array}{l}-0.18 \\
(0.47)\end{array}$ & $\begin{array}{l}-0.01 \\
(0.01)\end{array}$ & $\begin{array}{l}-0.66 \\
(0.40)\end{array}$ & $\begin{array}{l}-0.17 * * * \\
(0.01)\end{array}$ & $\begin{array}{l}-0.21 \\
(0.67)\end{array}$ & $(0.03)$ \\
\hline Precipitation & $\begin{array}{l}11.23 * * \\
(4.48)\end{array}$ & $\begin{array}{l}0.14 * * * \\
(0.01)\end{array}$ & $\begin{array}{l}5.83 \\
(7.54)\end{array}$ & $\begin{array}{l}0.04 * * * \\
(0.01)\end{array}$ & $\begin{array}{l}0.58 \\
(4.54)\end{array}$ & $\begin{array}{l}0.17 * * * \\
(0.00)\end{array}$ & $\begin{array}{l}2.04 \\
(3.38)\end{array}$ & $\begin{array}{l}0.06 * * * \\
(0.01)\end{array}$ \\
\hline $\begin{array}{l}\text { Precipitation } \\
\text { squared }\end{array}$ & $\begin{array}{l}-0.86 * * \\
(0.36)\end{array}$ & & $\begin{array}{l}-0.46 \\
(0.61)\end{array}$ & & $\begin{array}{l}-0.00 \\
(0.34)\end{array}$ & & $\begin{array}{l}-0.14 \\
(0.26)\end{array}$ & \\
\hline $\begin{array}{l}\text { Precipitation } \\
\text { anomaly }\end{array}$ & $\begin{array}{l}-0.02 \\
(0.11)\end{array}$ & $\begin{array}{l}-0.01 * * * \\
(0.01)\end{array}$ & $\begin{array}{l}0.02 \\
(0.12)\end{array}$ & $\begin{array}{l}0.03 * * * \\
(0.00)\end{array}$ & $\begin{array}{l}0.08 \\
(0.13)\end{array}$ & $\begin{array}{l}0.05 * * * \\
(0.00)\end{array}$ & $\begin{array}{l}0.08 \\
(0.10)\end{array}$ & $\begin{array}{l}0.02 * * * \\
(0.00)\end{array}$ \\
\hline Irrigation & $\begin{array}{l}0.48 * * \\
(0.21)\end{array}$ & $\begin{array}{l}0.10 * * * \\
(0.00)\end{array}$ & $\begin{array}{l}0.15 \\
(0.24)\end{array}$ & $\begin{array}{l}0.03 * * * \\
(0.00)\end{array}$ & $\begin{array}{l}0.10 \\
(0.22)\end{array}$ & $\begin{array}{l}0.03 * * * \\
(0.00)\end{array}$ & $\begin{array}{l}0.68 \\
(0.47)\end{array}$ & $\begin{array}{l}0.15 * * * \\
(0.01)\end{array}$ \\
\hline$R$-squared & 0.28 & 0.98 & 0.32 & 0.99 & 0.32 & 0.99 & 0.21 & 0.97 \\
\hline Observations & 2,471 & 2,478 & 2,010 & 2,010 & 1,394 & 1,394 & 1,123 & 1,123 \\
\hline
\end{tabular}

Notes: The dependent variable in columns (1) and (3) and (5) and (7) is respectively the log of sorghum and wheat yields, whereas in columns (2) and (4) and (6) and (8) is respectively the log of squared residuals. In the regression models, we control for zone and year fixed effects, farm inputs, farmer age, and education (see Table C4 in Appendix C). Standard errors are clustered at EA level and given in parentheses. $* * * p<0.01, * * p<0.05, * p<0.1$

its impact is statistically insignificant at high altitudes. On the other hand, the effect of precipitation anomaly on the variability of barley yield is positive at low altitudes whereas its effect is negative at high altitudes. Moreover, irrigation is found to be risk-reducing for the production of barley at low and high altitudes. This is reflected by the negative and statistically significant coefficient of irrigation in the model of barley yield variance. However, the effects of irrigation on the mean yield of barley are statistically insignificant.

\subsubsection{Maize yield}

As with coffee and barley, we find a heterogeneity in the impact of weather variables on the mean and variability of maize yield across altitudes. As shown in Table 3, temperature has a statistically significant and inverted U-shaped relationship with the mean yield of maize at high altitudes whereas its effect is statistically insignificant at low and middle altitudes. This suggests that maize yield increases with temperature up to a certain threshold beyond which the effect becomes negative. In addition, the variability of maize yield increases as 
Table 6 Estimation of models for full sample by including interactions of altitude with climate variables

\begin{tabular}{lllllll}
\hline Variables & $\begin{array}{l}\text { Coffee } \\
(1)\end{array}$ & $\begin{array}{l}\text { Barley } \\
(2)\end{array}$ & $\begin{array}{l}\text { Maize } \\
(3)\end{array}$ & $\begin{array}{l}\text { Teff } \\
(4)\end{array}$ & $\begin{array}{l}\text { Sorghum } \\
(5)\end{array}$ & $\begin{array}{l}\text { Wheat } \\
(6)\end{array}$ \\
\hline Temperature & -0.82 & $-1.51^{* *}$ & -0.08 & -0.57 & -1.01 & $-2.17 * * *$ \\
& $(2.11)$ & $(0.76)$ & $(0.56)$ & $(0.56)$ & $(0.69)$ & $(0.75)$ \\
Temperature*altitude & $1.72^{*}$ & $0.76^{* * *}$ & 0.14 & $0.33^{*}$ & $0.65 *$ & $0.94 * * *$ \\
& $(0.93)$ & $(0.28)$ & $(0.28)$ & $(0.20)$ & $(0.34)$ & $(0.26)$ \\
Precipitation & $2.59 * *$ & $0.67 *$ & 0.14 & $0.51 * *$ & $0.73 * * *$ & $1.29 * * *$ \\
& $(1.13)$ & $(0.36)$ & $(0.25)$ & $(0.20)$ & $(0.28)$ & $(0.33)$ \\
Precipitation*altitude & $-0.74 *$ & $-0.30^{* * *}$ & -0.06 & -0.12 & $-0.30^{*}$ & $-0.36 * * *$ \\
& $(0.43)$ & $(0.13)$ & $(0.12)$ & $(0.09)$ & $(0.16)$ & $(0.11)$ \\
$R$-squared & 0.40 & 0.25 & 0.28 & 0.32 & 0.25 & 0.26 \\
Observations & 1,089 & 2,300 & 5,536 & 3,865 & 4,481 & 2,517
\end{tabular}

The dependent variable in columns (1)-(6) is log of respective crops. The interactions between temperature and rainfall with altitude capture the heterogeneous impacts of respective climatic variables across different altitudes. In the regression models, we control for zone and year fixed effects, farm inputs, farmer age, and education (see Table E1 in Appendix E). Robust standard errors in parentheses. $* * * p<0.01, * * p<0.05$, $* p<0.1$

temperature increases at middle and high altitudes, but it decreases at low altitudes. Unlike temperature, precipitation has a U-shaped relationship with the mean yield of maize at high altitudes. The mean yield of maize initially declines as precipitation increases, but it starts increasing after a certain threshold. However, precipitation anomaly has a positive relationship with the mean maize yield at middle and high altitudes. The variability of maize yield increases as precipitation increases at middle and high altitudes but is reduced at low altitudes.

Furthermore, there is a difference in the impact of irrigation use on maize yield variability across altitudes. Irrigation decreases risks at low altitude, but it increases the risk at middle and high altitudes. On the other hand, we have obtained unexpected, but heterogeneous results about the impact of irrigation on the mean yield of maize. Irrigation is found to have a negative effect on the mean yield of maize at low altitude whereas its effect is positive at high altitude. The negative effect of irrigation on maize yield at low altitude contradicts with our expectation since the low altitude areas receive low levels of precipitation; irrigation is expected to increase yields. This may be due to the low adoption of irrigation practices among maize farmers in our sample.

\subsubsection{Teff yield}

Table 4 shows the estimated coefficients of weather variables in the teff yield model. Temperature has a U-shaped relationship with the mean yield of teff at high altitudes whereas its effects become statistically insignificant for the case of low and middle altitudes. The initial increase in temperature increases teff yield at the higher altitudes, but the effect becomes reversed after a certain threshold of temperature. That means that as temperature increases due to climate change, high altitude areas become suitable for teff production in the short term. In addition, temperature leads to increased teff production risk at low and middle altitudes whereas it decreases the production risk at low altitudes. 
Furthermore, precipitation has a statistically significant positive impact on the mean yield of teff at middle altitudes. Furthermore, an increase in precipitation increases the variance of teff yield at low and middle altitudes, whereas its effect on yield variability becomes negative for areas at high altitudes. Moreover, we find a positive relationship between irrigation and the mean yield of teff at low and middle altitudes, yet its effect is statistically insignificant at high altitudes. This suggests that farmers' adaptations to climate change by using irrigation can help to increase teff yield at low altitudes. Irrigation is also found to raise the variance of teff yield at all altitude levels.

\subsubsection{Sorghum yield}

In columns 1-4 of Table 5, we present the impacts of weather variables on the mean yield of sorghum and its variability. Temperature has a heterogeneous effect on the variance of sorghum yield at between low and middle altitudes. The positive changes in temperature induce the increase in the variability of sorghum yield at high altitudes whereas its impacts are negative at low altitudes. This result is statistically significant at the $1 \%$ level. On the other hand, precipitation has an inverted U-shaped relationship with the mean of sorghum yield at low altitudes whereas its effect is statistically insignificant at high altitudes. This result is also statistically significant at the 5\% level. If precipitation decreases beyond certain levels due to climate change, at low altitudes, sorghum yield will also decrease. Moreover, precipitation has a positive relationship with the variance of sorghum yields at both low and high altitudes. This is in line with results of Chen et al. (2004) who find a positive impact of precipitation on the variance of sorghum yield but it contrasts with the findings of McCarl et al. (2008) who report a negative effect. However, precipitation anomaly has a heterogeneous impact on the variability of sorghum yield. The variability of sorghum yield decreases at low altitude, but it rises at high altitudes when precipitation increases above the 1981-2010 average.

Another interesting result is how irrigation leads to an increase in the mean yield of sorghum at low altitudes, yet the result is statistically insignificant at high altitudes. Lowland areas receive less precipitation as compared to the places at high altitudes. Hence, the reduction of precipitation due to climate change can be damaging. In this regard, farmers' adaptation through irrigation to cope up with climate change-induced reduction in precipitation helps to increase the crop yields. This would suggest that the use of irrigation is crucial to building resilience and increase sorghum yields at low altitude areas. In addition, irrigation also increases the variability of the sorghum yield at both low and high altitudes.

\subsubsection{Wheat yield}

Our results also indicate the heterogeneity in the impacts of temperature on the mean yield of wheat between low and high altitudes in Ethiopia. Columns 5-8 in Table 5 present the estimates of the effects of weather variables on wheat yield and its variability. Our results indicate that temperature has an inverted U-shaped effect on mean wheat yield at high altitudes where its effect is statistically insignificant at low altitudes. The mean yield of wheat initially increases with higher temperatures at high altitudes, then it decreases after a certain threshold. Furthermore, precipitation, precipitation anomaly, and irrigation have a positive relationship with the variance of wheat yield at low and high altitudes. 


\subsection{Robustness check: estimations of full sample model and translog functional form}

To check the robustness of our results, we consider two alternative approaches for our empirical analysis. First, we undertake the regression analysis for the whole sample by including the interaction of altitude with rainfall and temperature instead of splitting the sample into low, middle, and high altitude sub-samples (Table 6). Second, we re-estimate our model using translog functional form instead of Cobb-Douglas specification reported in our original analysis (Tables 7). Our results about the positive effect of increasing temperature on coffee and teff yields at high altitudes are robust to considering the whole sample instead of separate estimation for low and high altitudinal locations. As shown in Table 6, the coefficient of interaction terms between temperature and altitude is positive and statistically significant. This finding is consistent with that presented in Table 2 and it implies that coffee and teff yield may increase, at least in the short run, as temperature increases due to climate change at high altitudes. Furthermore, the coefficients for barley and wheat are also consistent with the results obtained by estimating the model separately for low and high altitudes. The full results for whole sample model estimation including the interaction of altitude with temperature and precipitation for both mean and variance of crop yields are presented in Table E1 in the Supplementary Material.

In addition, the coefficient estimates for the impacts of temperature on coffee yield both at low and high altitude and barley, maize, and teff yields at high altitude carry on when we use translog functional form instead of the Cobb-Douglas form (see Table 7). These results show nonlinear and heterogeneous effects of temperature and precipitation on the crop yields. Specifically, temperature has a U-shaped relationship with coffee yield at low altitude, whereas the effects are inverted U-shaped at high altitudes. Similarly, temperature has an inverted U-shaped relationship with barley, maize, and teff yields at high altitudes. The full results for translog functional specification that included the estimation results for variance model are presented in Table E2 in the Supplementary Material.

\subsection{Impacts of future climate change on crop yields}

Using the estimated coefficients of temperature and precipitation given in Tables 2-5 and updated CMIP6 future emissions scenarios, we evaluate the impacts of future climate change on crop yields in Ethiopia. Table 8 shows the results for the projected impacts of climate change on the crop yields under low emission (SSP1-2.6), medium (SSP2-4.5), as well as medium-high (SSP3-7.0) and high (SSP5-8.5) emission scenarios. Table D1 in the Appendix D presents the medium-term impacts of climate change on crop yields for the period 2021-2040.

Under a medium emissions scenario (SSP2-4.5), results indicate that coffee yield decreases by about $3 \%$ at low altitude whereas there is a $31 \%$ increase at high altitudes due to climate change over 2041-2060 relative to 1988-2018 (see Table 8). Under the medium-high (SSP3-7.0) and high (SSP5-8.5) emission scenarios, the negative impact of climate change on coffee yield at low altitudes become lower, whereas its positive effects become higher at high altitudes as compared to the "middle of the road" (SSP2-4.5) scenario (see Table 8). The positive impact of climate change on coffee yield at high altitudes is due to the increasing temperature. Results from the recent studies also report heterogeneous of impacts across different agro-ecologies and more sensitivity of crop revenues to 


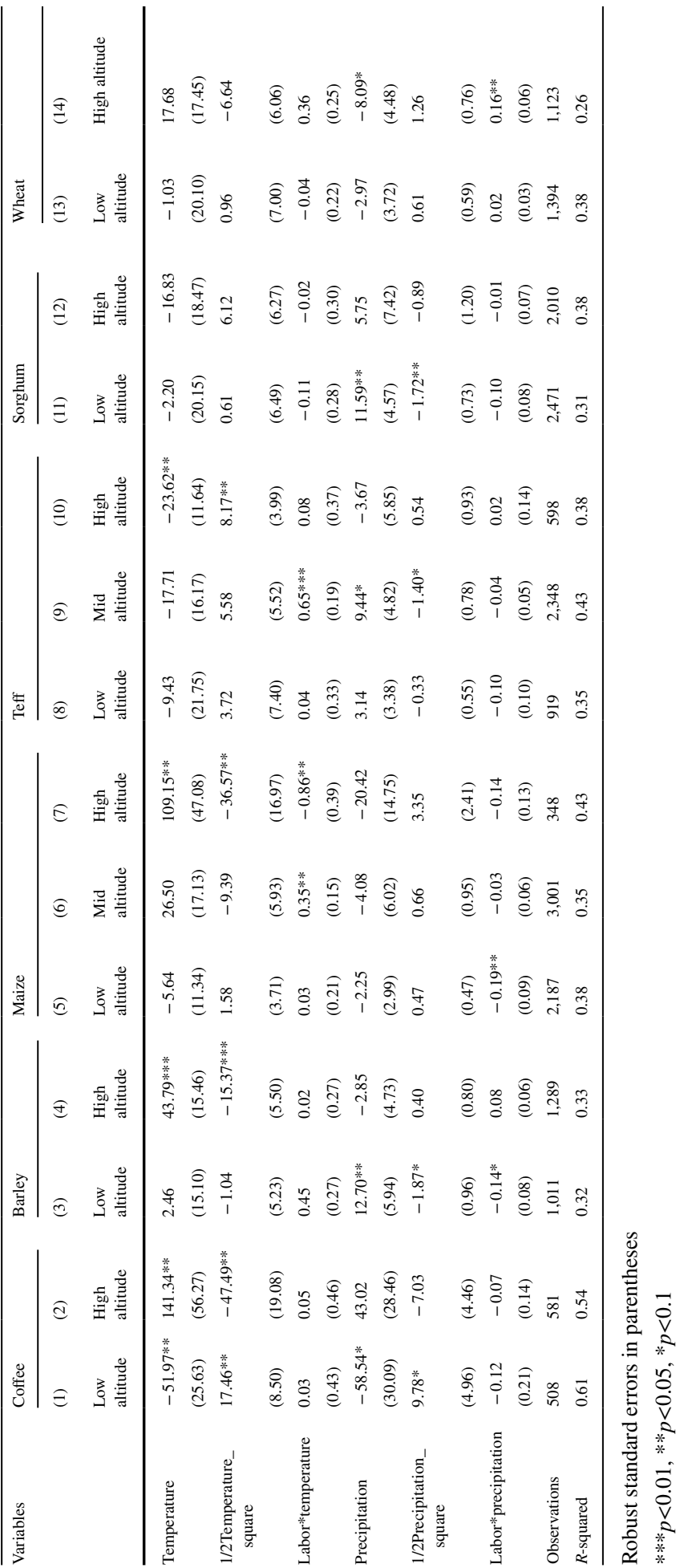


Table 8 Future climate change impacts on crop yields by 2041-2060

\begin{tabular}{|c|c|c|c|c|c|c|c|c|}
\hline \multirow[t]{3}{*}{ Crops } & \multicolumn{4}{|c|}{ Low altitudes } & \multicolumn{4}{|c|}{ High altitudes } \\
\hline & (1) & (2) & (3) & (4) & (5) & (6) & (7) & (8) \\
\hline & SSP1-2.6 & SSP2-4.5 & SSP3-7.0 & SSP5-8.5 & SSP1-2.6 & SSP2-4.5 & SSP3-7.0 & SSP5-8.5 \\
\hline Coffee & -4 & -2.89 & -1.8 & -0.31 & 24.58 & 31.03 & 31.7 & 33.26 \\
\hline Barley & & & & & -15.49 & -22.71 & -26.6 & -29.96 \\
\hline Maize & & & & & -59.76 & -66.98 & -78.52 & -85.92 \\
\hline Sorghum & 16.63 & 0.78 & 8.24 & 14.39 & & & & \\
\hline Teff & & & & & 4.45 & 8.29 & 8.93 & 10.26 \\
\hline Wheat & & & & & -6.62 & -9.95 & -12.95 & -13.65 \\
\hline
\end{tabular}

Notes: The numbers in columns (1)-(8) are percentages. The SSP1-2.6, SSP2-4.5, SSP3-7.0, and SSP5-8.5 represent low, medium, medium-high, and high emissions scenarios, respectively

temperature than rainfall (see e.g. Hossain et al. 2019). Compared to a medium emissions (SSP2-4.5) scenario, the positive impact of climate change on teff yield at high altitudes become higher under the medium-high (SSP3-7.0) and high (SSP5-8.5) emission scenarios and lower under a low emission (SSP1-2.6) scenario (see Table 8). We also find that climate change, reflected by changes in precipitation, induces an increase in sorghum yield.

On the other hand, our results show that barley, maize, and wheat yield decreases by $22.7 \%, 48 \%$, and $10 \%$ at high altitudes under SSP2-4.5 scenario, respectively, over 2041-2060 relative to 1988-2018. The negative impacts are driven by changes in temperature and precipitation becomes lower under a low emission scenario (SSP1-2.6) whereas it is higher under high emission scenarios, namely SSP3-7.0 and SSP5-8.5 (see Table 8). Our results are consistent with the findings of Arora et al. (2020) who reported 44\% and 58\% decline in maize and wheat yields due to climate change in the USA, but it contradicts with the finding of Jones and Thornton (2003) who predicted the benefit from climate change for wheat production at Ethiopian central highland areas. In addition, the negative effect of climate change on the mean yield of maize is partly consistent with the findings of Ray et al. (2019) for the case of maize yields in Togo. They report that maize yields experience a decrease in Southern districts in Togo whereas it increases in the Northern districts because of climate change; however, it is not clear if there are differences in altitudes between the two areas.

\section{Discussion and policy implication}

Our results illustrate that the heterogeneity in the impacts of climate change on coffee yield is mainly derived by the effect of temperature. An increase in temperature has an inverted U-shaped relationship with the mean yield of coffee at high altitudes, whereas its effect exhibits a U-shaped relationship at low altitudes (see Table 2). This nonlinear effect of temperature is consistent with the findings of previous literature such as Magrach and Ghazoul (2015) and Venancio et al. (2020) that the net photosynthesis process in coffee plants starts decreasing when temperatures go above $24{ }^{\circ} \mathrm{C}$ where it approaches zero when it becomes above $34{ }^{\circ} \mathrm{C}$ which hinders the development and ripening of cherries and reduces coffee plant growth. Moreover, under a medium emissions scenario, the results 
show that the coffee yield will increase by $31 \%$ at high altitudes, but it will decline by $3 \%$ low altitudes due to increase in temperature as a result of climate change over the period 2041-2060 relative to 1988-2018 (see Table 8). Our finding of positive impact of climate change on coffee yield is consistent with the prediction of previous studies in Brazil, Ethiopia, Nicaragua, Tanzania, and Uganda that climate change may create favorable conditions for coffee crop production at high altitudes (e.g., Camargo 2010; Läderach et al. 2017; Moat et al. 2017; Ovalle-Rivera et al. 2015; Rahn et al. 2018; Tavares et al. 2018). Several reasons are cited in the literature for the positive impact of temperature on coffee yield at high altitude areas. The elevated carbon concentration increases coffee yield at high altitudes (DaMatta et al. 2019; Rahn et al. 2018). In addition, the positive influence of climate change on coffee production results from increases in coffee-growing niches and pollination services (Pham et al. 2019).

Similarly, the results show that teff yield increases by $8.3 \%$ at high altitudes due to climate change by 2041-2060 compared to 1988-2018 under a medium emissions scenario. Considering the yearly variation, we find that precipitation and temperature have an inverted U-shaped relationship with the mean yield teff at middle and high altitudes, respectively. This result is partially inconsistent with the findings of existing literature about the prediction of decreasing teff production due climate change impacts on teff production in Ethiopia (Evangelista et al. 2013; Woldeyohannes et al. 2020), implying the need to consider disaggregated analysis across different agro-ecologies instead of aggregating the impacts of climate change for a whole teff producing areas in the country..

However, we find the negative impacts of climate change on barley, maize, and wheat yields at high altitudes. Specifically, the yields of barley, maize, and wheat crops will decline by $3 \%, 22.7 \%, 48 \%$, and $10 \%$ at high altitudes, respectively, over the period 2041-2060 relative to 1988-2018. Short-run variation in temperature has the inverted U-shaped relationship between the mean yield of barley, maize, and wheat at high altitudes. Our finding of inverted U-shaped effect of temperature on barley yield at high altitudes contradicts with the finding of Isik and Devadoss (2006) who report U-shaped relationship between mean yield of barley and temperature. On the other hand, our result about the effect of temperature variations on maize yield is consistent with the finding of previous literature about the impacts of climatic variables on maize production is Sub-Saharan Africa (Adisa et al. 2018; Cairns et al. 2013; Ray et al. 2019). The positive side of the nonlinear effect of temperature on the mean yield of wheat in highland areas is partly consistent with the findings of Poudel and Kotani (2013) who reported a positive relationship of temperature on the mean yield of wheat in Nepal. However, the negative sign of the coefficient of quadratic term indicates that yield starts to decrease after a certain threshold of the temperature. This result is consistent with the findings of Carew (2017) who reported the negative effect of temperature exceeding $34^{\circ}$ on the mean yield of wheat crop yield in Canada. In addition, precipitation has a U-shaped relationship with the mean yield of maize at high altitudes whereas its relationship with the mean yield of sorghum becomes inverted U-shaped at low altitudes. This result is consistent with the findings of Ray et al. (2019) who report an increase in sorghum yield due to recent climate change in Sub-Saharan African countries.

The general implication of our findings is that climate policies need to be informed by the location and crop-specific scenarios about the impacts of climate change besides those aggregated at national or regional levels. Therefore, identification of the locations that are becoming suitable and/or unsuitable for a specific crop is crucial to provide policy input regarding the comparative advantages for alternative crops and land uses (see, e.g., Arora et al. 2020). Furthermore, the suitability of crops to a given agro-ecology may change over 
time due to the changing climate. Therefore, it is necessary to keep updating the climate analyses and providing timely suggestions for policymakers to enhance agricultural productivity. There is also a need to provide the effective incentives to promote crop production in their respective climate-induced suitability areas. In this regard, agricultural policy programs, such as cluster farming, would better map crop suitability by considering future climate change and develop agro-ecological clusters instead of those based on traditional crop-growing geography. For instance, building coffee and teff clusters or commercialization centers at high altitudes can enhance climate resilience as these areas will become suitable for the two crops. Clustering farms can help not only to reduce the existing land fragmentation, but also to exploit synergies among climate adaptation practices and enhance farmers' food security (Cholo et al. 2019; Komarek et al. 2019).

\section{Concluding remarks}

This paper show that climate change may create favorable conditions for certain crops at high altitudes, whereas it harms the production of other crops. These heterogeneities in the impacts of climate change on crop yields across different altitudes suggest a need to design policy strategies to incorporate crop- and location-specific potential risks and opportunities pertaining to climate change in Ethiopia. Specifically, there is a need to devise climate adaptation strategies that suits different contexts and agro-ecological settings. Furthermore, it is necessary to provide evidence-based guidance and support for farmers to switch to crops suitable for their respective agro-ecological settings. This requires designing the specialized training for extension workers and rural development experts about the climate sensitivity of each crop at different micro-climate conditions and agro-ecologies in Ethiopia. Moreover, the government investment on irrigation dams should prioritize the areas vulnerable to droughts but also have high potential for crop yield enhancement. These strategies can help to build climate resilience, enhance crop productivity, and improve the livelihood of smallholder farmers in the face of climate change.

Finally, it is worth highlighting the main limitations of this paper which can serve as the basis for future research. First, the empirical analysis presented in this paper does not consider other factors that can interplay with climatic factors in determining crop growth and yields. Particularly, the crop evapotranspiration and atmospheric water demand, i.e., the level of vapor pressure deficit (VPD), can determine the effect of temperature and precipitation on crop farming process. ${ }^{4}$ In this regard, future studies may consider incorporating VPD into the analysis of climatic impacts on crop yields. Second, this paper does not incorporate the disparities in the impacts of climate change among different social groups. Therefore, future research is required to analyze the heterogeneity in climate change impacts across different social groups, such as gender, age, or income groups, within a similar agro-ecological setting. This can provide more detailed and useful insights into policy instruments to address variations in climate sensitivity among different groups and design effective strategies to achieve sustainable development goals.

Supplementary Information The online version contains supplementary material available at https://doi. org/10.1007/s10584-022-03306-1.

4 The author is grateful to an anonymous reviewer who suggested this key point. 
Acknowledgements The author wishes to thank a late Professor Emeritus Yves Surry for his advice and useful inputs during the early stage of this paper.

Funding Open access funding provided by Swedish University of Agricultural Sciences.

Open Access This article is licensed under a Creative Commons Attribution 4.0 International License, which permits use, sharing, adaptation, distribution and reproduction in any medium or format, as long as you give appropriate credit to the original author(s) and the source, provide a link to the Creative Commons licence, and indicate if changes were made. The images or other third party material in this article are included in the article's Creative Commons licence, unless indicated otherwise in a credit line to the material. If material is not included in the article's Creative Commons licence and your intended use is not permitted by statutory regulation or exceeds the permitted use, you will need to obtain permission directly from the copyright holder. To view a copy of this licence, visit http://creativecommons.org/licenses/by/4.0/.

\section{References}

Abadie A, Athey S, Imbens GW, Wooldridge J (2017) When should you adjust standard errors for clustering? National Bureau of Economic Research Working Paper Series No. 24003 https://doi.org/10. $3386 / w 24003$

Adisa OM et al (2018) Analysis of agro-climatic parameters and their influence on maize production in South Africa. Theoret Appl Climatol 134:991-1004. https://doi.org/10.1007/s00704-017-2327-y

Amede T, Auricht C, J.-M B, Dixon J, Mallawaarachchi T, M R, Deneke T (2017) A farming system framework for investment planning and priority setting in Ethiopia.

Arora G, Feng H, Anderson CJ, Hennessy DA (2020) Evidence of climate change impacts on crop comparative advantage and land use. Agric Econ 51:221-236. https://doi.org/10.1111/agec.12551

Auffhammer M (2018) Quantifying economic damages from climate change. Journal of Economic Perspectives 32:33-52. https://doi.org/10.1257/jep.32.4.33

Burke M, Emerick K (2016) Adaptation to Climate Change: Evidence from US Agriculture American Economic Journal. Economic Policy 8:106-140. https://doi.org/10.1257/pol.20130025

Cairns JE, Hellin J, Sonder K, Araus JL, MacRobert JF, Thierfelder C, Prasanna BM (2013) Adapting maize production to climate change in sub-Saharan Africa. Food Security 5:345-360. https://doi. org/10.1007/s12571-013-0256-X

Camargo MBPd (2010) The impact of climatic variability and climate change on arabic coffee crop in Brazil. Bragantia 69:239-247. https://doi.org/10.1590/S0006-87052010000100030

Carew R (2017) Climate change impacts on hard red spring wheat yield and production risk: evidence from Manitoba, Canada. Canadian Journal of Plant Science v. 98:pp. 782-795-2017 v.2098 no.2013 https://doi.org/10.1139/cjps-2017-0135

Carew R, Smith EG, Grant C (2009) Factors Influencing Wheat Yield and Variability: Evidence from Manitoba, Canada. Journal of Agricultural and Applied Economics 41:625-639. https://doi.org/10. 1017/S1074070800003114

Chen C-C, McCarl BA, Schimmelpfennig DE (2004) Yield Variability as Influenced by Climate: A Statistical Investigation. Climatic Change 66:239-261. https://doi.org/10.1023/B:CLIM.0000043159. 33816.e5

Chen S, Chen X, Xu J (2016) Impacts of climate change on agriculture: Evidence from China. J Environ Econ Manag 76:105-124. https://doi.org/10.1016/j.jeem.2015.01.005

Cholo TC, Fleskens L, Sietz D, Peerlings J (2019) Land fragmentation, climate change adaptation, and food security in the Gamo Highlands of Ethiopia. Agricultural Economics 50:39-49. https://doi. org/10.1111/agec.12464

DaMatta FM, Rahn E, Läderach P, Ghini R, Ramalho JC (2019) Why could the coffee crop endure climate change and global warming to a greater extent than previously estimated? Climatic Change 152:167-178. https://doi.org/10.1007/s10584-018-2346-4

Danyo S et al (2017) Ethiopia Country Environmental Analysis: Realizing Green Transformation. World Bank, Washington, DC

Esayas B, Simane B, Teferi E, Ongoma V, Tefera N (2018) Trends in Extreme Climate Events over Three Agroecological Zones of Southern Ethiopia. Advances in Meteorology 2018:17. https://doi. org/10.1155/2018/7354157 
Evangelista P, Young N, Burnett J (2013) How will climate change spatially affect agriculture production in Ethiopia? Case studies of important cereal crops. Clim Change 119:855-873. https://doi. org/10.1007/s10584-013-0776-6

FDRE (2011) Ethiopia's Climate-Resilient Green Economy strategy Federal Democratic Republic of Ethiopia (FDRE). Addis Ababa

Gebrechorkos SH, Hülsmann S, Bernhofer C (2019) Long-Term Trends in Rainfall and Temperature Using High-Resolution Climate Datasets in East Africa. Nat Sci Rep 9:11376. https://doi.org/10. 1038/s41598-019-47933-8

Hausfather Z (2019) CMIP6: The next generation of climate models explained.

Hossain MS, Arshad M, Qian L, Zhao M, Mehmood Y, Kächele H (2019) Economic impact of climate change on crop farming in Bangladesh: An application of Ricardian method. Ecol Econ 164:106354. https://doi.org/10.1016/j.ecolecon.2019.106354

Hurni H (1998) Agroecological Belts of Ethiopia. Explanatory notes on three maps at a scale of 1:1,000,000. Centre for Development and Environment, University of Bern, Switzerland

Isik M, Devadoss S (2006) An analysis of the impact of climate change on crop yields and yield variability. Applied Economics 38:835-844. https://doi.org/10.1080/00036840500193682

Jones PG, Thornton PK (2003) The potential impacts of climate change on maize production in Africa and Latin America in 2055. Glob Environ Change 13:51-59. https://doi.org/10.1016/S09593780(02)00090-0

Just RE, Pope RD (1978) Stochastic specification of production functions and economic implications. J Econ 7:67-86. https://doi.org/10.1016/0304-4076(78)90006-4

Kolstad CD, Moore FC (2019) Estimating the Economic Impacts of Climate Change Using Weather Observations. National Bureau of Economic Research, Working Paper No. 25537. Cambridge, MA

Komarek AM, Thurlow J, Koo J, De Pinto A (2019) Economywide effects of climate-smart agriculture in Ethiopia. Agric Econ 50:765-778. https://doi.org/10.1111/agec.12523

Läderach P, Ramirez-Villegas J, Navarro-Racines C, Zelaya C, Martinez-Valle A, Jarvis A (2017) Climate change adaptation of coffee production in space and time. Clim Change 141:47-62. https:// doi.org/10.1007/s10584-016-1788-9

Magrach A, Ghazoul J (2015) Climate and Pest-Driven Geographic Shifts in Global Coffee Production: Implications for Forest Cover Biodiversity and Carbon Storage. PLOS ONE 10:e0133071. https:// doi.org/10.1371/journal.pone.0133071

Manyazewal M, Shiferaw A (2019) Economic policy and structural transformation in Ethiopia. In: Cheru F, Cramer C, Oqubay A (eds) The Oxford Handbook of the Ethiopian Economy. Oxford University Press. https://doi.org/10.1093/oxfordhb/9780198814986.013.8

McCarl BA, Villavicencio X, Wu X (2008) Climate Change and Future Analysis: Is Stationarity Dying? Am J Agric Econ 90:1241-1247. https://doi.org/10.1111/j.1467-8276.2008.01211.x

Meinshausen M et al (2020) The shared socio-economic pathway (SSP) greenhouse gas concentrations and their extensions to 2500. Geoscientific Model Development 13:3571-3605. https://doi.org/10. 5194/gmd-13-3571-2020

Moat $\mathrm{J}$ et al (2017) Resilience potential of the Ethiopian coffee sector under climate change. Nature Plants 3:17081. https://doi.org/10.1038/nplants.2017.81

Ovalle-Rivera O, Läderach P, Bunn C, Obersteiner M, Schroth G (2015) Projected Shifts in Coffea arabica Suitability among Major Global Producing Regions Due to Climate Change. PloS one 10:e0124155. https://doi.org/10.1371/journal.pone.0124155

Pham Y, Reardon-Smith K, Mushtaq S, Cockfield G (2019) The impact of climate change and variability on coffee production: a systematic review. Clim Change 156:609-630. https://doi.org/10.1007/ s10584-019-02538-y

Picazo-Tadeo AJ, Wall A (2011) Production risk, risk aversion and the determination of risk attitudes among Spanish rice producers. Agricultural Economics 42:451-464. https://doi.org/10.1111/j. 1574-0862.2011.00537.x

Poudel S, Kotani K (2013) Climatic impacts on crop yield and its variability in Nepal: do they vary across seasons and altitudes? Climatic Change 116:327-355. https://doi.org/10.1007/ s10584-012-0491-8

Rahn E, Vaast P, Läderach P, van Asten P, Jassogne L, Ghazoul J (2018) Exploring adaptation strategies of coffee production to climate change using a process-based model. Ecol Model 371:76-89. https://doi.org/10.1016/j.ecolmodel.2018.01.009

Ray DK, West PC, Clark M, Gerber JS, Prishchepov AV, Chatterjee S (2019) Climate change has likely already affected global food production. PloS one 14:e0217148. https://doi.org/10.1371/journal. pone. 0217148 
Tavares PdS, Giarolla A, Chou SC, Silva AJdP, Lyra AdA (2018) Climate change impact on the potential yield of Arabica coffee in southeast Brazil. Regional Environmental Change 18:873-883. https:// doi.org/10.1007/s10113-017-1236-Z

Taye M, Simane B, Zaitchik BF, Selassie YG, Setegn S (2019) Rainfall Variability across the AgroClimatic Zones of a Tropical Highland: The Case of the Jema Watershed. Northwestern Ethiopia Environments 6:118

Venancio LP et al (2020) Impact of drought associated with high temperatures on Coffea canephora plantations: a case study in Espírito Santo State. Brazil Scientific Reports 10:19719. https://doi.org/ 10.1038/s41598-020-76713-y

Woldeyohannes AB, Accotto C, Desta EA, Kidane YG, Fadda C, Pè ME, Dell'Acqua M (2020) Current and projected eco-geographic adaptation and phenotypic diversity of Ethiopian teff (Eragrostis teff) across its cultivation range Agriculture. Ecosystems \& Environment 300:107020. https://doi.org/ 10.1016/j.agee.2020.107020

World Bank (2021) Climate Risk Country Profile: Ethiopia. The World Bank Group

Zhang P, Zhang J, Chen M (2017) Economic impacts of climate change on agriculture: The importance of additional climatic variables other than temperature and precipitation. J Environ Econ Manag 83:8-31. https://doi.org/10.1016/j.jeem.2016.12.001

Publisher's note Springer Nature remains neutral with regard to jurisdictional claims in published maps and institutional affiliations. 